\title{
Characterisation of Intergranular Corrosion in Austenitic Stainless Steel using Lock- in Thermography
}

\author{
by M.Menaka*,D.Sharath* and B.Venkatraman**
}

\author{
* Quality Assurance Division, Indira Gandhi Centre for Atomic Research, Kalpakkam-603102, Tamilnadu, India \\ , menaka@igcar.gov.in
}

${ }^{* *}$ Associate Director, Radiological and Envionmental Group, Indira Gandhi Centre for Atomic Research, Kalpakkam-603102, Tamilnadu, India, bvenkat@igcar.gov.in

\begin{abstract}
Intergranular corrosion (IGC) is one of the major localized corrosion problems faced by austenitic stainless steel (SS) components used in various industries. Conventional non-destructive methods such as ultrasonic, eddy current, radiography, etc., have the limitations in detecting the onset of localized corrosion, particularly at the earlier stage to have better understanding of the phenomenon. Hence, the use of lock-in thermography method to detect and monitor IGC at an early stage was explored in this work. AISI types 304 and 304LSS were subjected to sensitization heat treated at $675^{\circ} \mathrm{C}$ for $30 \mathrm{~min}, 1 \mathrm{hr}, 10 \mathrm{~h}, 100 \mathrm{~h}, 250 \mathrm{~h}$ and the IGC resistance was evaluated as per ASTM A262 Practice A (oxalic etch test) and double loop potentiokinetic reactivation (EPR) method. This paper dwells on the experimental approaches and the results obtained. Lock in thermography clearly indicates that it is a potential tool for early detection of sensitisation.
\end{abstract}

\section{Introduction}

Austenitic stainless steels are ductile, tough and most importantly easy to form and weld and hence are widely used as structural materials in strategic and core industries. One of the most widely used stainless steel is AISI type 304 and type 304L. The latter is preferred in more corrosive environment where welding is involved. Though these type of steels have high strength and excellent corrosion resistance, they are susceptible to intergranular corrosion (IGC) due to sensitisation. When these steels are heated or slowly cooled in the temperature range of $450^{\circ} \mathrm{C}$ to about $950^{\circ} \mathrm{C}$, chromium carbide can precipitate at the grain boundaries which in turn can lead to depletion of chromium in the vicinity of grain boundaries. This phenomenon is referred to as sensitisation. When sensitised austenitic stainless steel is exposed to a corrosive environment, the chromium depleted zones preferentially dissolve leading to inter granular corrosion (IGC). Sensitization is particularly important in welded metals. This is because the welding zone which also includes the heat affected zone (HAZ) can experience temperatures in the range that can cause sensitization. Sensitised microstructure in the presence of tensile stresses and corrosive environment can lead to intergranular stress corrosion cracking. In nuclear fuel cycle facilities at Kalpakkam, tanks and pipes which are predominantly fabricated using AISI type 304 SS are likely to have corrosive fluids such as nitric acid. During welding especially in cases of tanks wherein the dished end to the shell is normally done under restraint is likely to have tensile stresses. Hence in such cases it is essential to ensure that sensitisation does not occur during welding or fabrication. While adequate precautions are taken during welding, it is always preferable to have NDE methods to detect incipient sensitisation and / or localised corrosion before it can become a problem. Conventional nondestructive methods such as ultrasonic, eddy current, radiography, etc., have the limitations in detecting the onset of localized corrosion, particularly at the earlier stage to have better understanding of the phenomenon. Hence, the use of lock-in thermography method [1,2] to detect and monitor IGC at an early stage was explored in this work. This paper dwells on the experimental approaches and the results obtained.

\section{Experimental Approach Other headings as required}

AISI types 304 and $304 \mathrm{LSS}$ specimens were subjected to sensitization heat treated at $675^{\circ} \mathrm{C}$ for $30 \mathrm{~min}, 1 \mathrm{hr}$, $10 \mathrm{~h}, 100 \mathrm{~h}, 250 \mathrm{~h}$ and the IGC resistance was evaluated as per ASTM A262 Practice A (oxalic etch test) and double loop potentiokinetic reactivation (EPR) method. The detection of onset of IGC was assessed by Thermography.

Experimental Set Up: SILVER 420 IR camera (CEDIP) was used for the study which has Indium Antimonide semiconductor detector with $320 \times 256$ elements which detects IR radiation in the band $3.6 \mu \mathrm{m}-5.1 \mu \mathrm{m}$. The Stirling cooling system gives thermal resolution of $25 \mathrm{mK}$ and maximum achievable frame rate is $176 \mathrm{~Hz}$. For LT, two halogen lamps of power 1000 Watts were used as source of heat which was controlled using an amplifier and function generator. ALTAIR software was used for acquiring thermal images while ALTIR LI software was used for lock in analysis. The camera to object distance was kept at $35 \mathrm{~cm}$ and lamp to object distance was kept at $40 \mathrm{~cm}$. 


\section{Results and Discussion}

\subsection{Microstructure Results}

The microstructures of $304 \mathrm{SS}$ and $304 \mathrm{~L}$ SS specimens aged at $650^{\circ} \mathrm{C}$ for $30 \mathrm{~min}, 1 \mathrm{hr}, 10 \mathrm{hrs}, 100 \mathrm{hrs}$ and $250 \mathrm{hrs}$ were tested according to ASTM A262 Practice A test. It is noted from the table above that except for 30min of aging all the rest of the structures show ditch structure when examined in optical microscope at 250X for the 304 stainless steel specimens. In the case of stainless steel $304 \mathrm{~L}$ specimen step structure were noted until $1 \mathrm{hr}$ and dual structure at $10 \mathrm{hrs}$

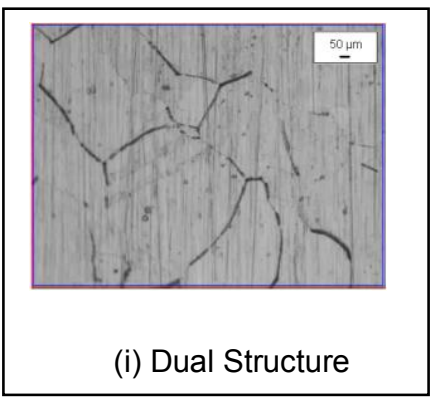

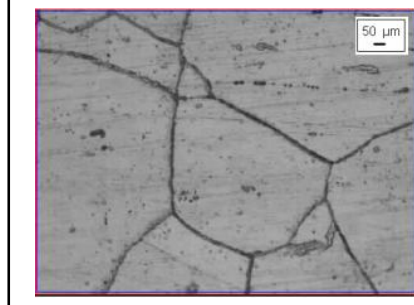

(ii) Ditch Structure

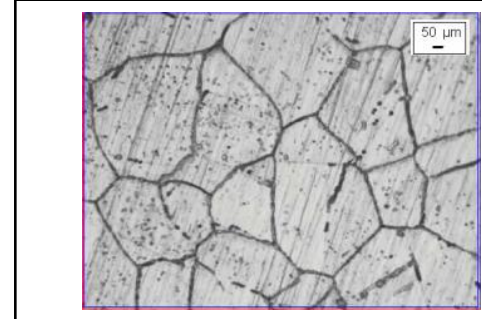

(iii) Ditch Structure

Fig.1.Microstructures obtained for SS304 from Practice A test for the aging durations(i)30mins (ii) 100h (iii) 250h
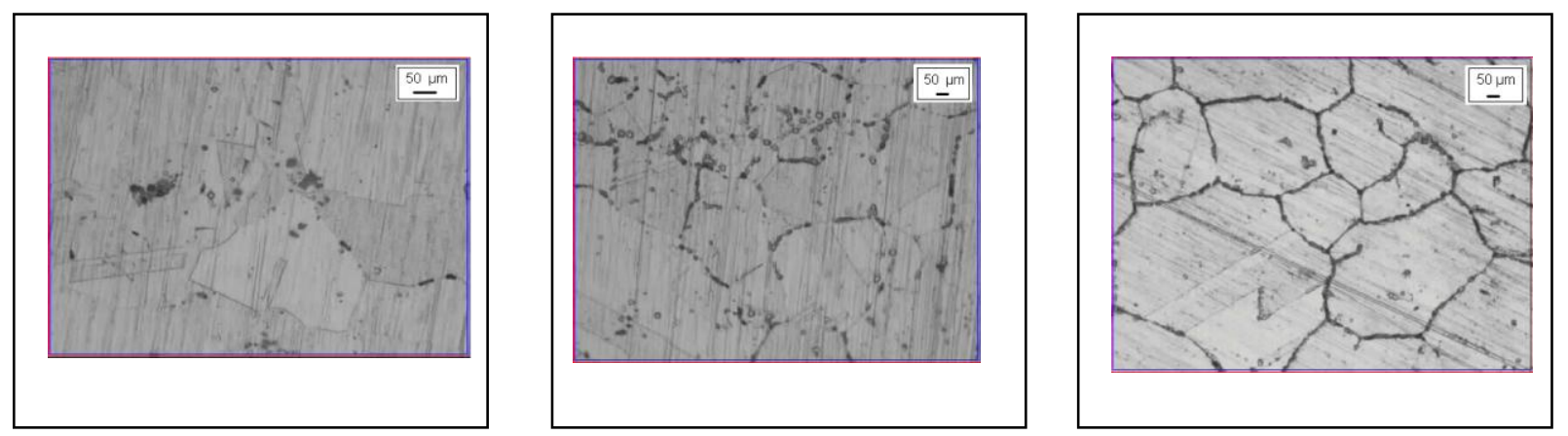

Fig. 2 Microstructures obtained for SS304L from Practice A test for the aging durations (i) 30mins (ii) $100 \mathrm{~h}$ (iii) $250 \mathrm{~h}$

\subsection{EPR Results}

The DL-EPR was used to find the Degree of Sensitization (DOS) of SS304 and SS 304L for different aging durations at $650^{\circ} \mathrm{C}$. From the plot drawn between current density and voltage, $l_{a}$ the peak reactivation current density of the anodic scan and $I_{r}$ the peak activation current density in the reversed scan were obtained. Such a plot between current density and voltage for SS 304 and SS304 L sensitized for $1 \mathrm{hr}$ at $650^{\circ} \mathrm{C}$ is given in figure 3 .
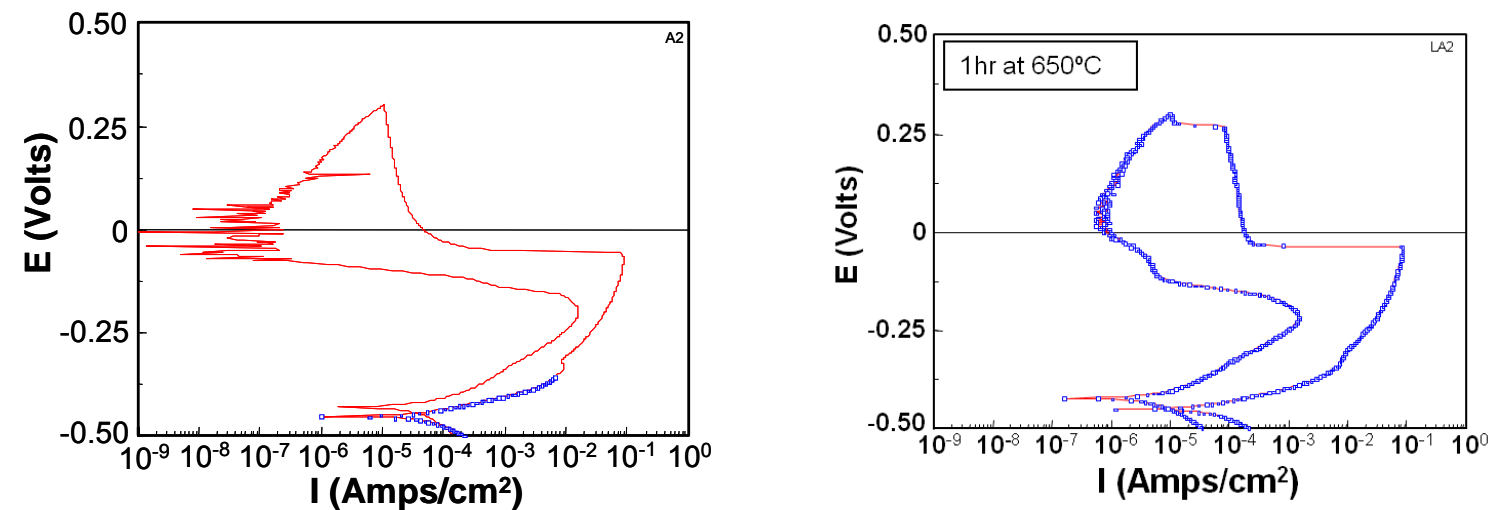

Fig. 3 Result for Double Loop EPR test of SS 304 subjected to sensitization for $1 \mathrm{hr}$ in $650^{\circ} \mathrm{C}$ in an air furnace. 
The results from Double Loop EPR test shows that the Degree Of Sensitization increases as aging duration increases. At $250 \mathrm{hr}$ the DOS value decreases slightly. This is attributed to the fact that peak value of sensitization lies between $100 \mathrm{hr}$ and $250 \mathrm{hr}$ of thermal aging duration. Hence the value seems to decrease slightly after $100 \mathrm{hr}$ of aging.

\subsection{Thermography Results}

The optimum frequency of $0.01 \mathrm{~Hz}$ was obtained based on maximum phase angle difference between before and after thermal aging specimens. The results revealed that the phase angle of the aged specimens increases with the increase in aging duration (See Fig.3). Phase angle difference between the specimens before and after thermal aged decreases with the increase in thermal aging duration. (See Fig.4). Correlation between phase angle and microstructure was also obtained.

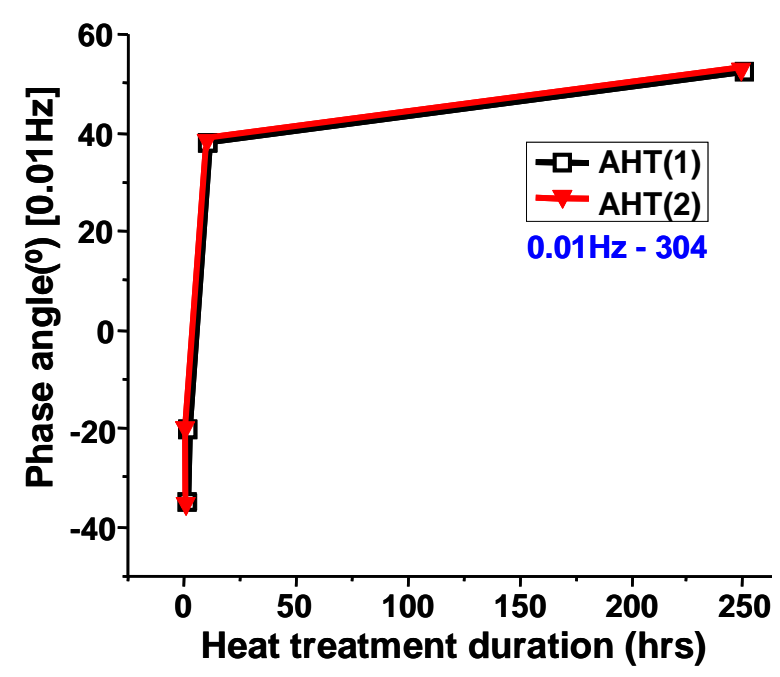

Fig. 4 Graph showing increase in phase angle with heat treatment duration

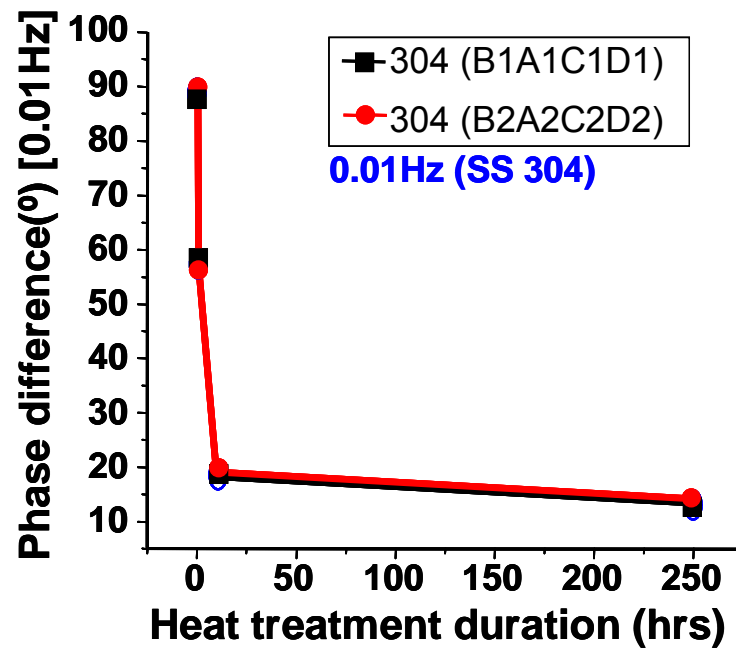

Fig. 5 Graph shows decrease in phase difference between un-aged and thermally aged specimens with increase in aging duration

\subsection{Conclusions}

The use of lock-in thermography method to detect and monitor IGC at an early stage was successfully explored in this work. Type SS 304L is more corrosion resistant than 304 SS which is confirmed from the results obtained from ASTM Practice A test. In Lock-in thermography, it was observed that the phase angle value of the sensitised specimen increased with the increase in thermal aging time. Good correlation was obtained for between the phase angle obtained from the thermal image, and the degree of sensitization (DOS) and the microstructure obtained.

\section{REFERENCES}

[1] Xavier P.V.Maldague, Non-Destructive Evaluation of Materials by Infrared Thermography, Springer Verlag, 1993, pp. 45.

[2] G. Busse, D. Wu, and W. Karpen, Thermal wave imaging with phase sensitive modulated thermography, J Appl. Phys. 71, 1992, pp. 3962-3965. 